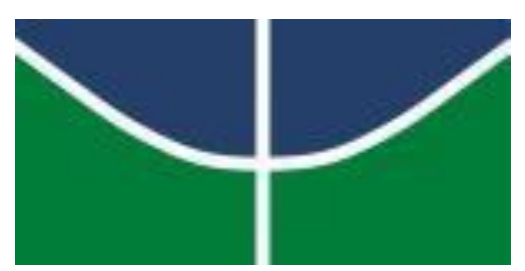

UNIVERSIDADE DE BRASÍLIA

FACULDADE DE CIÊNCIAS DA SAÚDE

DEPARTAMENTO DE ENFERMAGEM

NAYARA DAMASCENO DE SOUZA

ALEGAÇÕES DE MULHERES PARA A TOMADA DE DECISÃO EM RELAÇÃO À VIA DE PARTO: UMA REVISÃO INTEGRATIVA. 


\section{ALEGAÇÕES DE MULHERES PARA A TOMADA DE DECISÃO EM RELAÇÃO À VIA DE PARTO: UMA REVISÃO INTEGRATIVA.}

Trabalho de Conclusão de Curso, apresentado como requisito para Graduação no Curso de Enfermagem da Universidade de Brasília. O objetivo deste trabalho é identificar as alegações que levam as mulheres a decidir pela via de parto, normal ou cesárea.

Orientadora: Profa MSc. Mariana André Honorato Franzoi

\section{BRASÍLIA}




\section{ALEGAÇÕES DE MULHERES PARA A TOMADA DE DECISÃO EM RELAÇÃO À VIA DE PARTO: UMA REVISÃO INTEGRATIVA.}

Trabalho de Conclusão de Curso (TCC) apresentado como requisito parcial para obtenção do grau de Bacharel em Enfermagem pelo curso de Graduação em Enfermagem da Faculdade de Ciências da Saúde da Universidade de Brasília do campus Darcy Ribeiro.

Aprovado em

BANCA EXAMINADORA

Profa. Mestra Mariana André Honorato Franzoi

Universidade de Brasília (UnB)

Presidente

Profa. Dra. Rejane Antonello Griboski

Universidade de Brasília (UnB)

Membro Efetivo

Enfa. Obstetra Raquel Ribeiro Lira Diógenes

Secretaria de Estado de Saúde do Distrito Federal

Membro Efetivo

Profa. Dra. Rita de Cássia Melão de Morais

Universidade de Brasília (UnB)

Membro Suplente 


\section{DEDICATÓRIA}

Dedico este trabalho primeiramente a Deus, por ser essencial em minha vida e por ter me permitido chegar aonde cheguei, à minha mãe Jasciara por não ter medido esforços para que eu chegasse a essa etapa da minha vida, ao meu pai José Raimundo e aos meus irmãos Iara e Fábio por terem me apoiado nessa experiência. 


\section{AGRADECIMENTOS}

Agradeço à Universidade de Brasília pela oportunidade de realizar o curso de Enfermagem, ao Departamento de Enfermagem o qual precisei recorrer em muitos momentos do curso, ao Instituto de Psicologia que me apresentou os professores mais humanos que essa universidade possui, ao meu namorado Diego por me apoiar na escolha do curso e durante esse, mesmo em períodos estressantes, às minhas amigas Íris e Jéssica por terem feito parte dessa caminhada junto comigo, à minha tia Lúcia que sempre me apoiou em tudo na minha vida, aos meus avós maternos por acreditarem na minha capacidade e a todos que de alguma forma participaram dessa formação tão cansativa e gratificante. 


\section{RESUMO}

Introdução: Verifica-se uma alta taxa de cirurgia cesariana, principalmente em hospitais particulares, a qual está intimamente relacionada à morbimortalidade materno-infantil. Logo, faz-se necessário investigar o porquê do aumento contínuo deste tipo de parto, mesmo com recomendações da Organização Mundial de Saúde (OMS) para que essa taxa não ultrapasse os $15 \%$. É importante identificar se a opção pela cesárea ou parto normal está partindo da mulher e quais fontes de informação estão sendo utilizadas para fundamentar a tomada de decisão. Objetivo: Identificar as alegações que levam as mulheres a decidirem pelo tipo de parto, normal ou cesárea. Metodologia: Trata-se de Revisão Integrativa da literatura realizada nas bases de dados eletrônicas Medical Literature Analysis and Retrieval System on-line (PubMed/MEDLINE), Cumulative Index to Nursing and Allied Health Literature (CINAHL) e Literatura Latino-Americana e do Caribe em Ciências da Saúde (LILACS), a partir dos descritores "Decision Making"; "Natural Childbirth"; "Cesarean Section"; e a palavra-chave "Choice", assim como seus correspondentes em português. Resultados: Foram incluídos 16 estudos de abordagem qualitativa, que foram integrados em três eixos temáticos representativos das alegações das mulheres para a escolha do tipo/via de parto, a saber: motivações para escolha do parto normal, motivações para escolha da cesariana e fontes de informação motivadoras. Os principais motivos para a escolha pelo parto normal são recuperação puerperal mais rápida e benefícios para a saúde do recém-nascido. Já as mulheres que optam pela cesárea alegam essa escolha para fugir da dor e por medo do parto normal. As principais fontes de informação procuradas pelas mulheres para escolher a via de parto e obter conhecimentos sobre a gestação foram revistas, livros e internet. Destaca-se que em nenhum dos estudos analisados a enfermagem foi referida como fonte de informação pelas mulheres. Considerações Finais: É essencial a garantia de atendimento de pré-natal de qualidade, com escuta qualificada e compartilhamento de informações que possam fornecer subsídios às mulheres para que a escolha pela via de parto ocorra de forma consciente e orientada. Em especial, destaca-se o papel das enfermeiras, profissionais responsáveis pelo pré-natal de baixo risco, na orientação, esclarecimentos e compartilhamento de informações pertinentes que envolvem todo o processo de gestar e parir, evitando assim que as mulheres tomem decisões baseadas nas opiniões de familiares, amigos ou da mídia, que nem sempre refletem uma escolha baseada em evidências e segura.

Descritores: Tomada de decisão; Parto normal; Cesárea. 


\section{SUMÁRIO}

1. INTRODUÇÃ

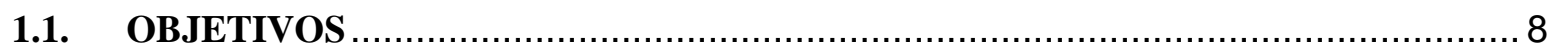

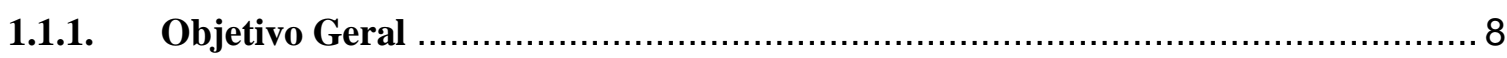

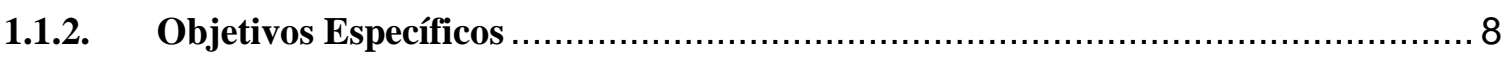

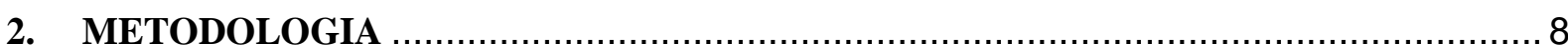

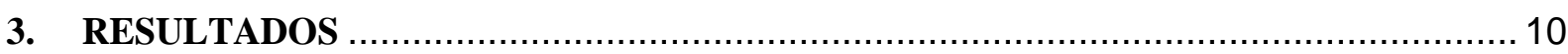

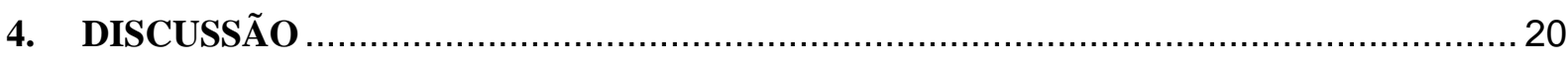

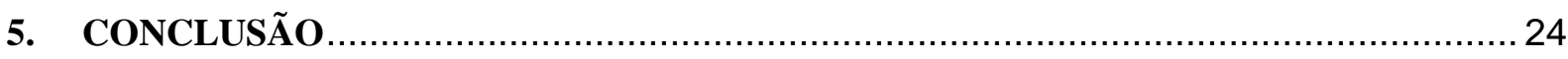

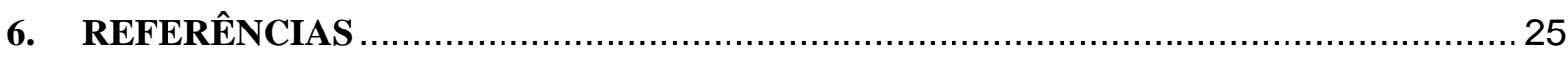

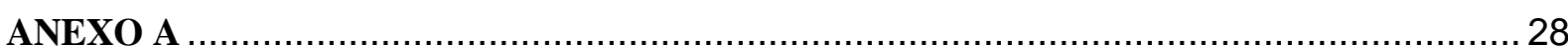




\section{INTRODUÇÃO}

Até o século XIX as mulheres brasileiras pariam em casa com o auxílio de parteiras. Porém, com o avanço das tecnologias, o parto hospitalizado foi ganhando mais força, principalmente a partir da década de 1960, assim como a ideia de que a mulher não era capaz de fazer esse trabalho sozinha (DINIZ \& CHACHAM, 2002; SANTOS et al. apud BRITO, 2013). Houve uma crescente desumanização do parto, com uma participação muito menor da mulher, que deveria ser a protagonista deste momento. No século XXI foram implementadas algumas iniciativas do governo para garantir um atendimento mais humanizado e de qualidade para as mulheres, como, por exemplo, o Programa de Humanização no Pré-natal e Nascimento (2000) e o Pacto Nacional pela Redução da Mortalidade Materna e Neonatal (2004), que visa monitorar a implementação de ações de proteção à saúde da criança e da mulher.

Apesar da implementação destas iniciativas, o parto medicalizado e cirúrgico continua crescendo no país. Culturalmente a cirurgia cesárea é considerada uma forma mais segura de parir, podendo ser realizada sem medo e a qualquer momento, inclusive por conveniência. É evidente a relação entre o crescimento contínuo da taxa de cesarianas e o aumento nas taxas de prematuridade e de morbimortalidade materno-infantil (LEAL et al., 2016).

Segundo a Escola Nacional de Saúde Pública (ENSP), o Brasil é o país com a maior taxa de cesáreas no mundo, aproximadamente 56\%, sendo que em hospitais da rede privada esta taxa pode chegar a 90\% (ENSP, 2016). A taxa de cirurgia cesariana foi aumentando com o passar do tempo; em 2005 era de 43.2\%, já em 2015 foi para 55.5\%, (BRASIL, 2016). Em comparação com os altos índices de cesariana, houve um aumento significativo nas taxas de prematuridade no decorrer dos anos. Em 2005, a taxa de prematuridade era de 5,5\%, já em 2015 esse valor subiu para 9,3\%, o que remete à uma associação entre o aumento do número de cesáreas e o aumento das taxas de prematuridade (LEAL et al., 2016).

Um estudo realizado em Mato Grosso do Sul mostrou que de 25 puéperas, 19 optaram por um parto normal, no entanto, apenas 10 conseguiram vivenciar este tipo de parto, evidenciando que muitas mulheres ainda consideram o parto normal a melhor opção, mas as vezes não conseguem realizá-lo (NASCIMENTO et al. 2015). Segundo o referido autor, uma das principais influências na escolha do tipo de parto é a experiência anterior; porém esta escolha também costuma ser influenciada pelos relatos de familiares e de pessoas próximas. 
Destaca-se, nesse contexto, o número crescente de gestantes que optam pela cesárea, sem nenhuma indicação real. Para Freire et al. (2011), o medo da dor ainda é um fator levado em consideração para essa opção de parto, o que é preocupante, pois revela que o pré-natal também não tem sido utilizado como espaço educativo e de esclarecimento às mulheres em relação aos tipos de parto e os riscos inerentes a cada um.

Verifica-se uma alta taxa de cirurgia cesariana, principalmente em hospitais particulares, a qual está intimamente relacionada à morbimortalidade materno-infantil. Logo, faz-se necessário investigar o porquê do aumento contínuo deste tipo de parto, mesmo com recomendações da Organização Mundial de Saúde (OMS) para que essa taxa não ultrapasse os $15 \%$ (atinge aproximadamente $90 \%$ em hospitais da rede privada). É importante identificar se a opção pela cesárea ou parto normal está partindo da mulher ou dos profissionais; e se parte da mulher, quais fontes de informação estão sendo utilizadas para fundamentar a tomada de decisão. Diante disso, propõe-se a seguinte questão de pesquisa: quais são as alegações das mulheres para a escolha do tipo de parto?

\subsection{OBJETIVOS}

\subsubsection{Objetivo Geral}

O objetivo deste trabalho é analisar as alegações que levam as mulheres a decidir pelo tipo de parto, normal ou cesárea.

\subsubsection{Objetivos Específicos}

- Conhecer as crenças das mulheres em relação à cesariana e ao parto normal;

- Identificar quais são as principais fontes de informação das mulheres para a tomada de decisão em relação ao tipo de parto.

\section{METODOLOGIA}

Trata-se de uma Revisão Integrativa da literatura, que consiste em agrupar e sintetizar pesquisas relacionadas a determinado tema em questão. Segundo Mendes et al. (2008), o método sistematiza e organiza resultados de pesquisa, de forma a contribuir para o aprofundamento do tema investigado. A revisão integrativa possibilita a identificação de 
lacunas de conhecimento, embasando a realização de novos estudos relacionados ao tema.

Para nortear essa revisão, utilizaram-se as seguintes questões: quais são as alegações das mulheres para a escolha do tipo de parto? Quais são as principais fontes de informação que influenciam as mulheres na escolha da via de parto?

Os artigos foram coletados a partir de três bases de dados eletrônicas: Medical Literature Analysis and Retrieval System on-line (PubMed/MEDLINE), Cumulative Index to Nursing and Allied Health Literature (CINAHL) e Literatura Latino-Americana e do Caribe em Ciências da Saúde (LILACS). Foram utilizados os seguintes descritores em inglês, assim como os seus correspondentes em português: "Decision Making" (tomada de decisão); "Natural Childbirth" (parto normal); "Cesarean Section" (cesárea). De maneira a complementar a busca, foi utilizada a palavra-chave "Choice" (escolha), que não consta no Descritores em Ciências da Saúde.

Os descritores foram dispostos de forma conjugada por meio do operador booleano "AND”. As combinações utilizadas foram: Decision Making AND Natural Childbirth (Tomada de decisão AND parto normal); Natural Childbirth AND Cesarean Section (Parto normal AND Cesárea) e Choice AND Natural Childbirth (Escolha AND Parto normal).

Os critérios de inclusão foram: estudos de abordagem qualitativa, publicados em português, inglês e/ou espanhol, relacionados à temática da escolha do tipo de parto pela mulher, que tivessem como participantes mulheres grávidas ou que já passaram por essa experiência do gestar e parir. Quanto aos critérios de exclusão, foram eliminados estudos que ultrapassaram 10 anos de publicação (2007 a 2017), que não possuíam resumo disponível e/ou que não estavam disponíveis gratuitamente na íntegra nas bases de dados, e/ou que tivessem como principais participantes profissionais da saúde ou familiares. Também foram excluídas as publicações na modalidade de editoriais, cartas, revisões, artigos de opinião, sínteses, comentários, notas prévias e artigos duplicados em mais de uma base de dados, considerando apenas um.

O processo de captação dos artigos nas bases de dados ocorreu de julho e agosto de 2017. Posteriormente, os artigos selecionados foram submetidos à leitura analítica e integral para extração de dados, através de um formulário elaborado pelas pesquisadoras, composto por: base de dados em que foi localizado, título, autor (es), ano de publicação, objetivos, delineamento metodológico da pesquisa, principais achados/resultados de cada estudo e principais conclusões, os quais foram categorizados e tabulados em planilhas do Excel, versão Microsoft Office 2010. Além disso, para avaliar o rigor metodológico dos estudos foi utilizado o instrumento intitulado de "Critical Appraisal Skills Programme (CASP) - Qualitative 
Research Checklist" (Anexo A).

\section{RESULTADOS}

Obteve-se um total de 1.195 (mil cento e noventa e cinco) artigos nas três bases, sendo 57 (cinquenta e sete) na CINAHL, 711 (setecentos e onze) na MEDLINE e 427 (quatrocentos e vinte e sete) na LILACS. Após leitura de título e resumo, elegeram-se 31 artigos para leitura na íntegra, dos quais 16 compuseram a amostra final (Figura 1). Os quadros 1, 2 e 3 resumem os motivos de exclusão em cada uma das três bases de dados de acordo com as combinações de descritores.

Figura 1. Fluxograma segundo critérios de seleção dos estudos, Brasília, 2018.

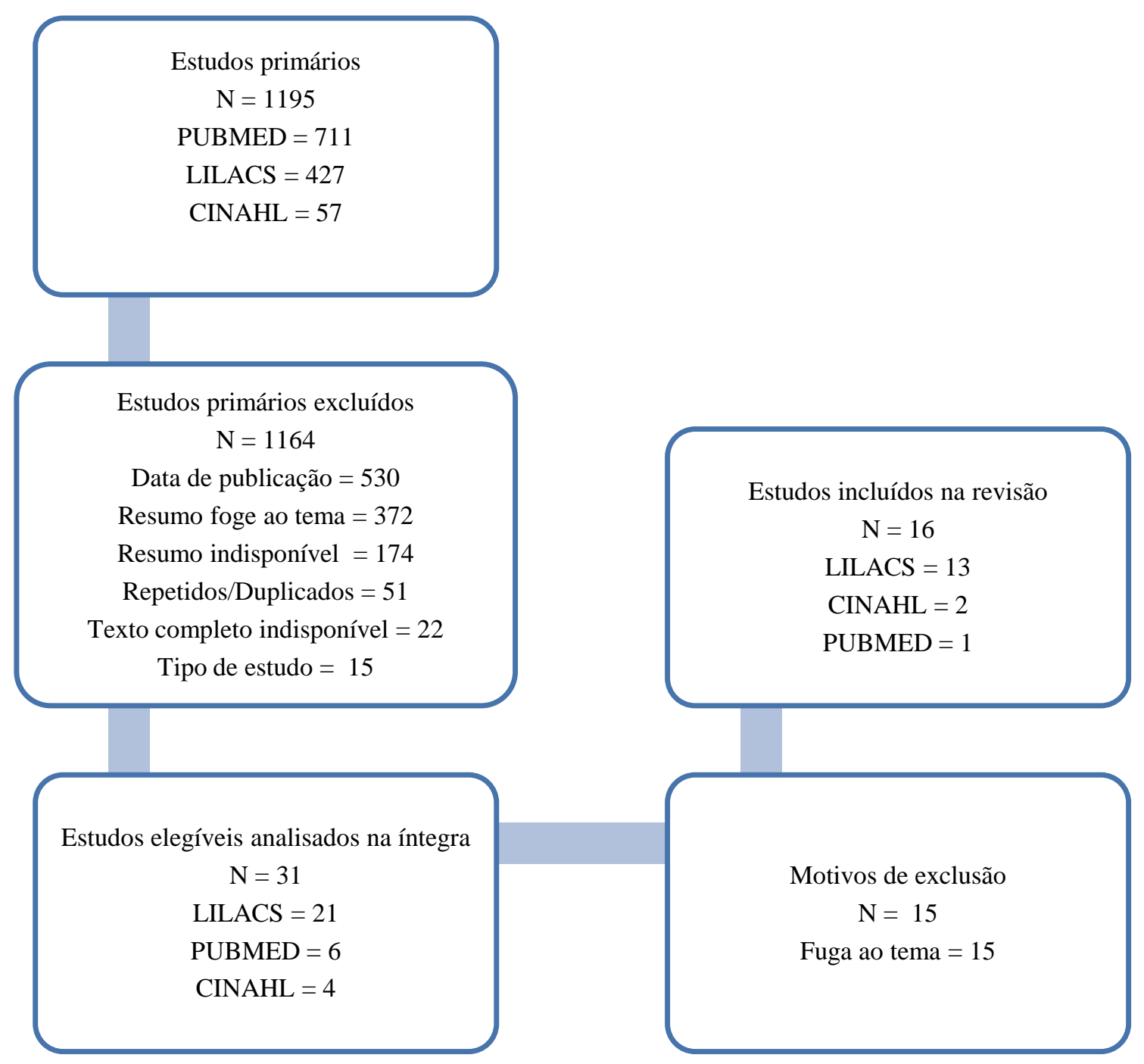


Quadro 1. Motivos de exclusão dos estudos localizados na base de dados CINAHL, de acordo com as combinações de descritores. Brasília, 2018.

\begin{tabular}{|c|c|c|c|c|c|c|c|c|c|c|c|c|}
\hline Base & $\begin{array}{l}\text { Combinação de } \\
\text { descritores }\end{array}$ & $\begin{array}{l}\text { Número } \\
\text { de artigos }\end{array}$ & $\begin{array}{c}\text { Artigo } \\
\text { publicado } \\
\text { antes de } \\
2007 \\
\end{array}$ & $\begin{array}{c}\text { Resumo } \\
\text { indisponível }\end{array}$ & $\begin{array}{l}\text { Artigo } \\
\text { repetido }\end{array}$ & $\begin{array}{c}\text { Resumo } \\
\text { foge ao } \\
\text { tema }\end{array}$ & $\begin{array}{c}\text { Texto não } \\
\text { disponível } \\
\text { na íntegra }\end{array}$ & $\begin{array}{l}\text { Tipo de } \\
\text { estudo }\end{array}$ & Idioma & $\begin{array}{c}\text { Fuga ao } \\
\text { tema }\end{array}$ & $\begin{array}{c}\text { Rigor } \\
\text { metodológico }\end{array}$ & $\begin{array}{c}\text { Artigos } \\
\text { selecionados }\end{array}$ \\
\hline \multirow{4}{*}{ CINAHL } & $\begin{array}{c}\text { Decision Making } \\
\text { AND Natural } \\
\text { Childbirth } \\
\end{array}$ & 14 & 3 & 2 & - & 4 & - & 3 & - & 2 & - & 0 \\
\hline & $\begin{array}{l}\text { Natural Childbirth } \\
\text { AND Cesarean } \\
\text { Section }\end{array}$ & 30 & 12 & 9 & 3 & 4 & - & - & - & - & - & 2 \\
\hline & $\begin{array}{c}\text { Choice AND } \\
\text { Natural Childbirth }\end{array}$ & 13 & 4 & 3 & 2 & 4 & - & - & - & - & - & 0 \\
\hline & Total & 57 & 19 & 14 & 5 & 12 & 0 & 3 & 0 & 2 & 0 & 2 \\
\hline
\end{tabular}

Quadro 2. Motivos de exclusão dos estudos localizados na base de dados LILAC'S, de acordo com as combinações de descritores. Brasília, 2018.

\begin{tabular}{|c|c|c|c|c|c|c|c|c|c|c|c|c|}
\hline Base & $\begin{array}{l}\text { Combinação de } \\
\text { descritores }\end{array}$ & $\begin{array}{c}\text { Número } \\
\text { de artigos }\end{array}$ & \begin{tabular}{|c} 
Artigo \\
publicado \\
antes de \\
2007
\end{tabular} & $\begin{array}{c}\text { Resumo } \\
\text { indisponível }\end{array}$ & $\begin{array}{l}\text { Artigo } \\
\text { repetido }\end{array}$ & $\begin{array}{c}\text { Resumo } \\
\text { foge ao } \\
\text { tema }\end{array}$ & $\begin{array}{l}\text { Texto não } \\
\text { disponível } \\
\text { na íntegra }\end{array}$ & $\begin{array}{l}\text { Tipo de } \\
\text { estudo }\end{array}$ & Idioma & $\begin{array}{c}\text { Fuga ao } \\
\text { tema }\end{array}$ & $\begin{array}{c}\text { Rigor } \\
\text { metodológico }\end{array}$ & $\begin{array}{c}\text { Artigos } \\
\text { selecionados }\end{array}$ \\
\hline \multirow{4}{*}{ LILAC'S } & $\begin{array}{l}\text { Tomada de decisão } \\
\text { AND Parto normal }\end{array}$ & 5 & 2 & - & - & 2 & - & - & - & - & - & 1 \\
\hline & $\begin{array}{l}\text { Parto normal AND } \\
\text { Cesárea }\end{array}$ & 384 & 186 & 24 & 1 & 151 & - & 5 & - & 6 & - & 11 \\
\hline & $\begin{array}{c}\text { Escolha AND Parto } \\
\text { normal }\end{array}$ & 38 & 8 & - & 10 & 17 & - & - & - & 2 & - & 1 \\
\hline & Total & 427 & 196 & 24 & 11 & 170 & 0 & 5 & 0 & 8 & 0 & 13 \\
\hline
\end{tabular}

Quadro 3. Motivos de exclusão dos estudos localizados na base de dados MEDLINE, de acordo com as combinações de descritores. Brasília, 2018.

\begin{tabular}{|c|c|c|c|c|c|c|c|c|c|c|c|c|}
\hline Base & $\begin{array}{l}\text { Combinação de } \\
\text { descritores }\end{array}$ & $\begin{array}{c}\text { Número } \\
\text { de artigos }\end{array}$ & \begin{tabular}{|c} 
Artigo \\
publicado \\
antes de \\
2007 \\
\end{tabular} & $\begin{array}{c}\text { Resumo } \\
\text { indisponível }\end{array}$ & $\begin{array}{l}\text { Artigo } \\
\text { repetido }\end{array}$ & $\begin{array}{c}\text { Resumo } \\
\text { foge ao } \\
\text { tema }\end{array}$ & $\begin{array}{c}\text { Texto não } \\
\text { disponível } \\
\text { na íntegra }\end{array}$ & $\begin{array}{l}\text { Tipo de } \\
\text { estudo }\end{array}$ & Idioma & $\begin{array}{l}\text { Fuga ao } \\
\text { tema }\end{array}$ & $\begin{array}{c}\text { Rigor } \\
\text { metodológico }\end{array}$ & $\begin{array}{c}\text { Artigos } \\
\text { selecionados }\end{array}$ \\
\hline \multirow{4}{*}{$\begin{array}{l}\text { MEDLI } \\
\text { NE }\end{array}$} & $\begin{array}{c}\text { Decision Making } \\
\text { AND Natural } \\
\text { Childbirth }\end{array}$ & 224 & 74 & 76 & 1 & 42 & 20 & 6 & - & 4 & - & 1 \\
\hline & $\begin{array}{l}\text { Natural Childbirth } \\
\text { AND Cesarean } \\
\text { Section }\end{array}$ & 343 & 185 & 29 & 17 & 110 & 1 & - & - & 1 & - & 0 \\
\hline & $\begin{array}{c}\text { Choice AND } \\
\text { Natural Childbirth }\end{array}$ & 144 & 56 & 31 & 17 & 38 & 1 & 1 & - & - & - & 0 \\
\hline & Total & 711 & 315 & 136 & 35 & 190 & 22 & 7 & 0 & 5 & 0 & 1 \\
\hline
\end{tabular}

A maioria dos artigos foi publicada em português $(n=13 / 81,25 \%)$, seguida por 03 $(18,75 \%)$ artigos publicados em inglês. Dos 16 artigos analisados, 13 foram publicados no Brasil, 02 no Irã e 01 na África do Sul.

Quanto ao período de publicação, os anos de 2013, 2014 e 2015 tiveram maior quantidade de publicação, 03 artigos em cada ano. Em 2010 e 2011 foram publicados 4 artigos, 2 em cada ano, já nos anos de 2009, 2016 e 2017 contou-se apenas com 01 
publicação/ano.

Em relação à pontuação no CASP, a média obtida foi de 7,2 pontos. De acordo com Sousa \& Santana (2016), os estudos analisados pelo instrumento podem ser agrupados em duas categorias; são elas: artigos de boa qualidade metodológica e com viés reduzido (entre 06 e 10 pontos) e estudos com qualidade metodológica satisfatória, porém com potencial para viés aumentado (05 pontos). Dos 16 artigos submetidos à análise pelo instrumento, 14 obtiveram pontuação entre 06 e 10 pontos, e 02 apresentaram pontuação igual a 05 , nenhum estudo obteve pontuação inferior a 05. Dessa forma, verifica-se que a maioria dos artigos que compuseram esta revisão apresentam boa qualidade metodológica e viés reduzido.

Quanto às revistas em que os estudos foram publicados, foram encontradas 14 revistas/jornais diferentes, com destaque para seis periódicos brasileiros de enfermagem com Qualis Periódicos CAPES entre B2 e A2, são elas: Revista Brasileira de Enfermagem (Qualis A2), Revista Cogitare Enfermagem (Qualis B1), Revista Gaúcha de Enfermagem (Qualis B1) Revista de Enfermagem do Centro Oeste Mineiro (Qualis B2) - com dois estudos, Revista de Pesquisa: Cuidado é fundamental Online (Qualis B2) - também com dois estudos, Revista Baiana de Enfermagem (Qualis B2). Além da Revista Interação em Psicologia, Physis: Revista de Saúde Coletiva, Revista Saúde e Sociedade, Revista Brasileira de Saúde Materno Infantil, Feminism \& Psychology, HURevista, Revista Midwifery e Iranian journal of nursing and midwifery research.

Abaixo encontra-se um quadro em que consta um resumo com os principais achados de cada estudo. 
Quadro 04. Síntese descritiva dos estudos incluídos na revisão. Brasília, 2018.

\begin{tabular}{|c|c|c|c|}
\hline \begin{tabular}{|l|} 
Autor (ano) \\
\end{tabular} & Título & Objetivo & Principais resultados \\
\hline $\begin{array}{c}\text { Bittencourt et } \\
\text { al. } 2013\end{array}$ & $\begin{array}{l}\text { Concepção de } \\
\text { gestantes sobre o } \\
\text { parto cesariano. }\end{array}$ & $\begin{array}{l}\text { Investigar os motivos que levam a } \\
\text { mulher a optar pela cesariana, } \\
\text { conhecer as crenças e os fatores } \\
\text { culturais que se sobressaem } \\
\text { durante a gestação e que podem } \\
\text { influenciar na escolha da via de } \\
\text { parto, e investigar quais orientações } \\
\text { as gestantes tiveram sobre os } \\
\text { diferentes tipos de parto. }\end{array}$ & $\begin{array}{l}\text { Os resultados apontaram a dor e a influência familiar e } \\
\text { cultural como interferentes na escolha da via do parto. } \\
\text { Embora as gestantes confirmem ter recebido, em algum } \\
\text { momento, orientações, ao serem questionadas sobre as } \\
\text { vantagens e desvantagens das diferentes vias de parto, as } \\
\text { participantes não conseguiram expô-las, ainda, as } \\
\text { gestantes informaram que as orientações foram dadas } \\
\text { pelo obstetra, por professores universitário e/ou foram } \\
\text { adquiridas em palestras, livros e meios de } \\
\text { comunicação.Nenhuma gestante citou o profissional } \\
\text { enfermeiro como educador e orientador em saúde. }\end{array}$ \\
\hline $\begin{array}{l}\text { Carneiro et } \\
\text { al. } 2015\end{array}$ & $\begin{array}{l}\text { Parto natural X parto } \\
\text { cirúrgico: percepções } \\
\text { de mulheres que } \\
\text { vivenciaram os dois } \\
\text { momentos. }\end{array}$ & $\begin{array}{c}\text { Analisar as percepções de } \\
\text { mulheres sobre suas vivências entre } \\
\text { parto natural e parto cirúrgico. }\end{array}$ & $\begin{array}{l}\text { As mulheres entrevistadas relataram que o parto natural } \\
\text { dói, mas é melhor do que o parto cirúrgico; que o parto } \\
\text { cirúrgico é realizado antes do trabalho de parto e que é } \\
\text { programado para a realização da laqueadura. Os } \\
\text { resultados evidenciaram, ainda, que as mulheres se } \\
\text { apresentam mais integradas ao parto como um processo } \\
\text { e não como um evento. }\end{array}$ \\
\hline $\begin{array}{l}\text { Chadwick \& } \\
\text { Foster, } 2013\end{array}$ & $\begin{array}{l}\text { Tecnologias de } \\
\text { gênero e opções de } \\
\text { parto: parto } \\
\text { domiciliar, cesariana } \\
\text { eletiva e feminilidade } \\
\text { branca na África do } \\
\text { Sul. }\end{array}$ & $\begin{array}{c}\text { Expandir a literatura sobre } \\
\text { "escolhas" de parto em relação ao } \\
\text { parto domiciliar e cesariana eletiva } \\
\text { e traçar as maneiras pelas quais as } \\
\text { "escolhas" das mulheres para parir } \\
\text { em casa ou por meio de uma } \\
\text { cesárea eletiva são moldadas por } \\
\text { contextos sócio-culturais de gênero } \\
\text { e relações de poder ultilizando o } \\
\text { conceito de "tecnologias de } \\
\text { gênero". }\end{array}$ & $\begin{array}{l}\text { Um dos principais achados foi que as opções de parto } \\
\text { das mulheres são fortemente moldadas por tecnologias de } \\
\text { poder baseadas no gênero. As decisões das mulheres } \\
\text { sobre o parto não ocorrem dentro de um vácuo } \\
\text { sociocultural; discursos mais amplos sobre o corpo das } \\
\text { mulheres, a reprodução e a feminilidade moldam e } \\
\text { policiam suas escolhas. }\end{array}$ \\
\hline $\begin{array}{l}\text { Faisal et al. } \\
2014\end{array}$ & $\begin{array}{c}\text { Por que os } \\
\text { primigestas pedem } \\
\text { uma cesariana em } \\
\text { uma gravidez normal? } \\
\text { Um estudo qualitativo } \\
\text { no Irã. }\end{array}$ & $\begin{array}{l}\text { O objetivo deste estudo foi } \\
\text { determinar por que as mulheres } \\
\text { iranianas solicitaram cesárea } \\
\text { durante a primeira gravidez, na } \\
\text { ausência de qualquer indicação } \\
\text { médica conhecida. }\end{array}$ & $\begin{array}{l}\text { A análise identificou quatro temas principais: (1) medo do } \\
\text { parto vaginal como um evento assustador e terrível, com } \\
\text { dor e lesão intolerável para a mãe e o bebê; (2) } \\
\text { preocupação com complicações após o parto vaginal; e } \\
\text { (3) as mulheres confiavam em seus médicos; e (4) as } \\
\text { mulheres não confiavam no pessoal das áreas de parto e } \\
\text { enfermarias de parto. A maioria dos participantes baseou } \\
\text { suas opiniões nas experiências de outras mulheres que } \\
\text { tiveram parto vaginal e na mídia devido à educação pré- } \\
\text { natal insuficiente e inadequada e à baixa conscientização } \\
\text { das mulheres iranianas em relação ao parto. }\end{array}$ \\
\hline $\begin{array}{c}\text { Feitosa et al. } \\
2017\end{array}$ & $\begin{array}{c}\text { Fatores que } \\
\text { influenciam a escolha } \\
\text { do tipo de parto na } \\
\text { percepção das } \\
\text { puérperas. }\end{array}$ & $\begin{array}{c}\text { Analisar os fatores que influenciam } \\
\text { a escolha do tipo de parto por } \\
\text { parte das puérperas de } \\
\text { Mossoró/RN. }\end{array}$ & $\begin{array}{l}\text { As puérperas apontam o desejo de um parto sem } \\
\text { intercorrências e com recuperação rápida. São } \\
\text { significativas as influências do "medo da dor" e das } \\
\text { experiências individuais e de outras mulheres para a } \\
\text { escolha da via de parto. }\end{array}$ \\
\hline
\end{tabular}


Quadro 04 (continuação). Síntese descritiva dos estudos incluídos na revisão. Brasília, 2018.

\begin{tabular}{|c|c|c|c|}
\hline Autor (ano) & Título & Objetivo & Principais resultados \\
\hline $\begin{array}{l}\text { Figueiredo et } \\
\text { al. } 2010\end{array}$ & $\begin{array}{l}\text { Fatores culturais } \\
\text { determinantes da } \\
\text { escolha da via de } \\
\text { parto por gestantes. }\end{array}$ & $\begin{array}{l}\text { Conhecer as crenças e os fatores } \\
\text { culturais que atuam no período de } \\
\text { gestação e podem influenciar na } \\
\text { escolha da mulher por determinada } \\
\text { via de parto. }\end{array}$ & $\begin{array}{l}\text { As gestantes sinalizaram sua preferência pelo parto } \\
\text { normal, mais natural e humanizado, contrariando o } \\
\text { modelo hospitalar e medicalizado predominante hoje em } \\
\text { dia. As justificativas apontam o desejo de um parto sem } \\
\text { intercorrências e com recuperação rápida. } \\
\text { São significativas as influências do "medo da dor" e das } \\
\text { experiências individuais e de outras mulheres. }\end{array}$ \\
\hline $\begin{array}{c}\text { Freire et al. } \\
2011\end{array}$ & $\begin{array}{c}\text { Parto normal ou } \\
\text { cesárea? A decisão } \\
\text { na voz das mulheres. }\end{array}$ & $\begin{array}{l}\text { Descrever o processo de tomada } \\
\text { de decisão das mulheres sobre a } \\
\text { via de parto e identificar fatores } \\
\text { associados à decisão pela via de } \\
\text { parto vaginal ou cesárea. }\end{array}$ & $\begin{array}{c}58,3 \% \text { das entrevistadas desejavam ter parto normal; } \\
\text { dessas, apenas } 16,7 \% \text { tiveram seu desejo atendido. } \\
\text { Todas as mulheres que desejavam a cesárea durante a } \\
\text { gestação (41,6\%) conseguiram fazer valer a sua escolha, } \\
\text { sem dificuldade. Os resultados mostram um processo de } \\
\text { decisão sobre a via de parto centrado no saber médico, } \\
\text { supostamente indiscutível, reafirmando a hegemonia do } \\
\text { conhecimento e do poder médico sobre o corpo das } \\
\text { mulheres. }\end{array}$ \\
\hline $\begin{array}{l}\text { Matão et al. } \\
2016\end{array}$ & $\begin{array}{c}\text { Fatores que } \\
\text { influenciam na } \\
\text { indicação da via de } \\
\text { parto. }\end{array}$ & $\begin{array}{c}\text { Conhecer os fatores que } \\
\text { influenciam na escolha da via de } \\
\text { parto, na perspectiva de gestantes, } \\
\text { puérperas e médicos obstetras. }\end{array}$ & $\begin{array}{l}\text { A grande maioria das gestantes apresentou opção por um } \\
\text { tipo, com o predomínio da cesariana sobre o normal e } \\
\text { poucas ainda não haviam definido a via de parto, mas } \\
\text { tenderam pelo parto vaginal. A familia e a sociedade, a } \\
\text { condição socioeconômica, além dos medos e receios, } \\
\text { pessoais e familiares, para com o parto sustentaram os } \\
\text { argumentos apresentados pelos participantes desta } \\
\text { pesquisa, justificando suas opiniões em relação à via de } \\
\text { parto. }\end{array}$ \\
\hline $\begin{array}{c}\text { Melchiori et } \\
\text { al. } 2009\end{array}$ & $\begin{array}{c}\text { Preferência de } \\
\text { gestantes pelo parto } \\
\text { normal ou cesariano. }\end{array}$ & $\begin{array}{l}\text { Investigar a preferência pelo tipo } \\
\text { de parto entre as gestantes e os } \\
\text { motivos da preferência e Investigar } \\
\text { se a gestante teme, ou não, o } \\
\text { momento do parto, quais suas } \\
\text { justificativas e o que minimiza o } \\
\text { temor. }\end{array}$ & $\begin{array}{l}\text { A maioria das gestantes (75\%) relatou preferir o parto } \\
\text { normal, principalmente porque acreditam ter uma rápida } \\
\text { recuperação e ser melhor para elas e/ou bebês. } 15 \% \text { das } \\
\text { gestantes preferiram a cirurgia cesariana porque } \\
\text { consideram ser um parto sem dor e essas preferências, } \\
\text { em geral, foram influenciadas por amigas. A maioria das } \\
\text { gestantes afirmou que diante do parto temem: sentir } \\
\text { dor/sofrer, acontecer algo com elas e/ou bebês, a } \\
\text { situação desconhecida ou avaliada como negativa e a } \\
\text { presença de pessoas de confiança, como o marido, a mãe } \\
\text { ou o médico, poderia minimizar esse temor. }\end{array}$ \\
\hline
\end{tabular}


Quadro 04 (continuação). Síntese descritiva dos estudos incluídos na revisão. Brasília, 2018.

\begin{tabular}{|c|c|c|c|}
\hline Autor (ano) & Título & Objetivo & Principais resultados \\
\hline $\begin{array}{c}\text { Nakano et al. } \\
2015\end{array}$ & $\begin{array}{c}\text { A normalização da } \\
\text { cesárea como modo } \\
\text { de nascer: cultura } \\
\text { material do parto em } \\
\text { maternidades privadas } \\
\text { no Sudeste do Brasil. }\end{array}$ & $\begin{array}{c}\text { Discutir o desenvolvimento de uma } \\
\text { cultura material em torno do parto } \\
\text { e do nascimento em um contexto } \\
\text { de utilização maciça de inovações } \\
\text { tecnocientíficas e explorar a } \\
\text { hipótese da normalização da } \\
\text { cesariana como modo de nascer. }\end{array}$ & $\begin{array}{c}\text { Ao pensarem na cesariana, as mulheres não colocam a } \\
\text { possibilidade de não aceitação do médico. A situação de } \\
\text { recusa médica, de fato, não foi relatada. Em alguns casos, } \\
\text { no início da gravidez, profissionais ponderaram que a } \\
\text { decisão sobre o parto deveria ser tomada "mais adiante". } \\
\text { Entre as mulheres, duas haviam cogitado realizar um parto } \\
\text { vaginal e sete não haviam descartado de todo essa } \\
\text { possibilidade no início da gravidez. As visões do parto } \\
\text { vaginal como mais doloroso, mais arriscado para bebês e } \\
\text { mães, mais lesivo para o corpo e a sexualidade da mulher } \\
\text { e de cesáreas salvadoras atuam de modo importante na } \\
\text { elaboração de valores relacionados ao parto e ao } \\
\text { nascimento. }\end{array}$ \\
\hline $\begin{array}{c}\text { Nascimento } \\
\text { et al. } 2015\end{array}$ & $\begin{array}{l}\text { Escolha do tipo de } \\
\text { parto: fatores } \\
\text { relatados por } \\
\text { puérperas. }\end{array}$ & $\begin{array}{c}\text { Conhecer os fatores relatados por } \\
\text { puérperas que influenciaram na } \\
\text { escolha pelo tipo de parto. }\end{array}$ & $\begin{array}{l}76 \% \text { das participantes manifestaram preferência pela } \\
\text { realização do parto normal. Dessas, } 40 \% \text { foram } \\
\text { submetidas à cesárea, } 36 \% \text { escolheram e alcançaram o } \\
\text { parto normal; } 20 \% \text { escolheram e tiveram parto cirúrgico. } \\
\text { Apenas } 4 \% \text { (uma) não tinha preferência. A tomada de } \\
\text { decisão foi baseada em experiências anteriores e a } \\
\text { possibilidade de repetição do mesmo tipo de parto, tanto } \\
\text { normal quanto operatório. As experiências prévias com o } \\
\text { parto, interferências familiares, interação profissional } \\
\text { influenciaram na escolha do tipo de parto. }\end{array}$ \\
\hline $\begin{array}{c}\text { Pereira et al. } \\
2011\end{array}$ & $\begin{array}{c}\text { Representações } \\
\text { sociais e decisões das } \\
\text { gestantes sobre a } \\
\text { parturição: } \\
\text { protagonismo das } \\
\text { mulheres. }\end{array}$ & $\begin{array}{c}\text { Compreender como se dá o } \\
\text { protagonismo da mulher nas } \\
\text { decisões sobre a parturição a partir } \\
\text { de suas representações sociais. }\end{array}$ & $\begin{array}{l}\text { Da análise dos dados emergiram três categorias } \\
\text { empíricas, manifestadas nos depoimentos das } \\
\text { entrevistadas e que expressaram suas representações } \\
\text { sociais: medos e preocupações, vivências e influência } \\
\text { sociocultural. A partir delas foi possível construir três } \\
\text { categorias interpretativas: modelo biomédico, } \\
\text { desinformação e autonomia da mulher. }\end{array}$ \\
\hline $\begin{array}{c}\text { Pimenta et al. } \\
2013\end{array}$ & $\begin{array}{l}\text { A cultura interferindo } \\
\text { no desejo sobre o } \\
\text { tipo de parto. }\end{array}$ & $\begin{array}{l}\text { Compreender de que forma a } \\
\text { cultura influencia no processo de } \\
\text { parturição da mulher. }\end{array}$ & $\begin{array}{c}\text { Os resultados mostram que a via de parto desejada pela } \\
\text { maioria das entrevistadas foi o parto normal, mas } \\
\text { constatou-se que a maioria não conseguiu realizar esse } \\
\text { desejo, devido à influência e às intervenções recebidas do } \\
\text { médico. }\end{array}$ \\
\hline
\end{tabular}


Quadro 04 (continuação). Síntese descritiva dos estudos incluídos na revisão. Brasília, 2018.

\begin{tabular}{|c|c|c|c|}
\hline Autor (ano) & Título & Objetivo & Principais resultados \\
\hline $\begin{array}{c}\text { Pires et al. } \\
2010\end{array}$ & $\begin{array}{c}\text { A influência da } \\
\text { assistência profissional } \\
\text { em saúde na escolha } \\
\text { do tipo de parto: um } \\
\text { olhar sócio } \\
\text { antropológico na } \\
\text { saúde suplementar } \\
\text { brasileira. }\end{array}$ & $\begin{array}{l}\text { Contribuir para a compreensão da } \\
\text { influência da assistência profissional } \\
\text { em saúde na escolha do tipo de } \\
\text { parto de gestantes atendidas pelos } \\
\text { serviços de saúde suplementar. }\end{array}$ & $\begin{array}{l}\text { Os resultados mostraram alta incidência de parto cesáreo } \\
\text { e entre os fatores que contribuíram para este fenômeno } \\
\text { identificou-se a medicalização do processo gravidez- } \\
\text { parto, o medo da dor, a conveniência da data marcada e } \\
\text { um processo de negociação/orientação que se estabelece } \\
\text { entre a gestante e seus familiares e o profissional médico, } \\
\text { fortemente influenciado pelo vínculo de confiança dessa } \\
\text { relação. Fatores culturais, experiências anteriores, } \\
\text { relações familiares e a assistência pré natal baseada na } \\
\text { biomedicina também influenciaram a favor do parto } \\
\text { cesáreo. A preferência pela via de parto já realizada é } \\
\text { mantida em próximas gestações. }\end{array}$ \\
\hline $\begin{array}{l}\text { Velho et al. } \\
2014\end{array}$ & \begin{tabular}{|c} 
Parto normal e \\
cesárea: \\
representações sociais \\
de mulheres que os \\
vivenciaram.
\end{tabular} & $\begin{array}{c}\text { Conhecer as representações sociais } \\
\text { do parto normal e da cesárea para } \\
\text { mulheres que os vivenciaram. }\end{array}$ & $\begin{array}{l}\text { Os resultados revelam, na vivência da maternidade, } \\
\text { representações como: a busca de informações; o } \\
\text { vivenciar da parturição sozinha versus acompanhada; e a } \\
\text { mulher não tem opção de escolha. O parto normal } \\
\text { engloba temas centrais como: ambivalência de } \\
\text { sentimentos; percepção positiva e hospitalização. A } \\
\text { cesárea está relacionada com ambivalência de } \\
\text { sentimentos, a solução de um problema e à preferência } \\
\text { pela cesárea. }\end{array}$ \\
\hline $\begin{array}{l}\text { Zakerihamidi } \\
\text { et al. } 2014\end{array}$ & $\begin{array}{l}\text { Tomada de decisão } \\
\text { para o parto vaginal } \\
\text { no norte do Irã: uma } \\
\text { etnografia enfocada. }\end{array}$ & $\begin{array}{c}\text { Explorar os determinantes da } \\
\text { tomada de decisão para o parto } \\
\text { vaginal no norte do Irã, a partir da } \\
\text { perspectiva das mulheres. }\end{array}$ & $\begin{array}{l}\text { O estudo mostra que um dos fatores mais citados para } \\
\text { escolha do parto normal é o fator econômico - a maioria } \\
\text { das participantes acredita que a cesárea é mais cara. A } \\
\text { maioria dos obstetras sugerem o parto normal e tentam } \\
\text { mudar a ideia da gestante quando ela escolhe uma } \\
\text { cesariana. "Cinco temas foram extraídos dos dados: } \\
\text { fatores de influência econômica, valores culturais e } \\
\text { normas relacionadas ao parto normal, atitudes positivas } \\
\text { em relação ao parto vaginal, papel de outros importantes } \\
\text { e facilitadores do parto natural." }\end{array}$ \\
\hline
\end{tabular}

Todos os estudos incluídos foram de abordagem qualitativa e utilizaram entrevistas semiestruturas e/ou abertas em profundidade como estratégia para coleta de dados. Ao todo, contaram-se 398 participantes com idade entre 14 e 55 anos, sendo 212 gestantes, 127 mulheres que já vivenciaram o parto (normal, cirúrgico ou ambos) e 59 puérperas.

A partir da integração dos resultados foi possível identificar três eixos temáticos representativos das alegações das mulheres para a escolha do tipo/via de parto, a saber: motivações para escolha do parto normal, motivações para escolha da cesariana e fontes de informação motivadoras. Serão descritos apenas fatores relatados pelas mulheres (gestantes, puérperas ou mulheres que já vivenciaram o parto).

\section{Motivações para escolha do parto normal}

Os estudos referem a preferência pelo parto normal justificada, em sua grande maioria, 
pela recuperação mais rápida (NASCIMENTO et al. 2015; PIMENTA et al. 2013, BITTENCOURT et al. 2013; FIGUEIREDO et al. 2010; FEITOSA et al. 2017) e pela dor momentânea durante o parto (MELCHIORI et al. 2009; FEITOSA et al. 2017). Outro motivo bastante citado foi o fato de ser melhor para a mãe e para o bebê, considerando inclusive a melhor preparação do bebê para vir ao mundo (NASCIMENTO et al. 2015; FEITOSA et al. 2017). A facilidade para amamentar também é colocada como um fator motivador (ZAKERIHAMIDI et al. 2014; MELCHIORI et al. 2009; NASCIMENTO et al. 2015). A noção de que um parto normal oferece menos riscos tanto à mãe quanto para o bebê foi outra motivação referida pelas mulheres (BITTENCOURT et al. 2013; PIMENTA et al. 2013; PEREIRA et al. 2011). Algumas gestantes têm a ideia de que a cesárea é mais cara do que o parto normal e alegam esse fator para optarem por essa via de parto (ZAKERIHAMIDI et al. 2014; MELCHIORI et al. 2009). Contudo, é ressaltado que quando a escolha da mulher é por um parto normal, ela nem sempre é atendida ( FREIRE et al. 2011).

\section{Motivações para escolha da cesariana}

O principal motivo para a escolha da cesárea como via de nascimento, segundo os estudos analisados, é o medo da dor, sendo este repetido em onze dos dezesseis artigos verificados (FAISAL et al. 2014; FEITOSA et al. 2017; MELCHIORI et al. 2009; PEREIRA et al. 2011; BITTENCOURT et al. 2013; VELHO et al. 2014; PIMENTA et al. 2013; NAKANO et al. 2015; NASCIMENTO et al. 2015; MATÃO et al. 2016; FREIRE et al. 2011). A velocidade do nascimento e a possibilidade de agendar a data, deixando tudo mais prático e cômodo, também foram relatadas em algumas pesquisas (NAKANO et al. 2015; VELHO et al. 2014; PEREIRA et al. 2011; PIRES et al. 2010). A realização da laqueadura logo após o parto foi relatada como uma justificativa em três estudos (BITTENCOURT et al. 2013; FIGUEIREDO et al. 2010; CARNEIRO et al, 2015). A presença de alguma condição clínica que pode aumentar o potencial para complicações, como hipertensão materna, também foi citada (FREIRE et al. 2011; FIGUEIREDO et al. 2010; FEITOSA et al. 2017; PIRES et al. 2010). A ideia de que o parto normal oferece riscos e mais sofrimento ao bebê e que a cesárea é uma forma de evitá-los foi alegada pela mulheres (NASCIMENTO et al. 2015; NAKANO et al. 2015; FIGUEIREDO et al. 2010; FAISAL et al. 2014). Além disso, a realização de cesárea anterior foi apontada como motivação em dois estudos (FREIRE et al. 2011; NASCIMENTO et al. 2015). Experiências ruins durante partos normais anteriores ou relato de conhecidos que tiveram más vivências, como, por exemplo, a não permissão da presença do acompanhante foram também motivações para a escolha da cesariana (FAISAL et al. 2014; VELHO et al. 2014). 


\section{Fontes de informação motivadoras}

As principais fontes de informação procuradas pelas mulheres para escolher a via de parto e obter conhecimentos sobre a gestação foram revistas, livros e internet (NASCIMENTO et al. 2015; NAKANO et al. 2015; VELHO et al. 2014; BITTENCOURT et al. 2013; FIGUEIREDO et al. 2010). No entanto, a opinião de familiares e pessoas próximas, principalmente quando essas pessoas são mulheres que já tiveram alguma experiência de parto, se mostrou, segundo os estudos analisados, mais eficaz do que as outras fontes citadas (MATÃO et al. 2016; FIGUEIREDO et al. 2010; FAISAL et al. 2014; ZAKERIHAMIDI et al. 2014). Algumas gestantes relataram ter obtido informações por meio do médico (BITTENCOURT et al. 2013; FIGUEIREDO et al. 2010; VELHO et al. 2014; MELCHIORI et al. 2009), outras relataram obterem informações a partir de filmes, novelas, televisão e vídeos (MATÃO et al. 2016; VELHO et al. 2014; FIGUEIREDO et al. 2010; MELCHIORI et al. 2009).

Os estudos apontaram o déficit de informações durante o pré-natal como um fator dificultador para o empoderamento das mulheres na tomada de decisão consciente em relação à via de parto (PIRES et al. 2010; FEITOSA et al. 2017; FREIRE et al. 2011). Diante disso, sugeriram a participação do enfermeiro da atenção básica em estratégias para munir as gestantes de informações sobre o processo de gestação, parto e pós-parto (NASCIMENTO et al. 2015; BITTENCOURT et al. 2013), considerando que não foi observado na fala das gestantes o(a) enfermeiro(a) como fonte de informação e orientações (BITTENCOURT et al. 2013).

O quadro abaixo mostra as alegações das gestantes agrupadas de acordo com as três categorias identificadas: 
Quadro 5. Exemplos de relatos de mulheres agrupados de acordo com as principais motivações para escolha da via de parto e de fontes de informação. Brasília, 2018.

\begin{tabular}{|c|c|c|}
\hline \multirow{6}{*}{$\begin{array}{l}\text { Motivações para a } \\
\text { escolha do parto } \\
\text { normal }\end{array}$} & Rápida recuperação & $\begin{array}{l}\text { "Eu quero parto normal pela recuperação mais rápida para poder voltar } \\
\text { a estudar." (Pimenta et al. 2013); "É melhor, devido à recuperação que é } \\
\text { mais rápida." (Nascimento et al. 2015); "a recuperação, pra mãe cuidar } \\
\text { do filho, não depender dos outros, porque na cesárea você vai depender } \\
\text { de alguém." (Figueiredo et al. 2010) }\end{array}$ \\
\hline & Melhor para o bebê & $\begin{array}{l}\text { "O bebê nasce na data de modo mais natural, ele tem uma preparação } \\
\text { pra saber que está vindo ao mundo, então parece que sai mais } \\
\text { preparado." (Nascimento et al. 2015); "o momento que o bebê escolhe } \\
\text { vir ao mundo, quando ele sabe que está pronto e bem formado." (Feitosa } \\
\text { et al. 2017) }\end{array}$ \\
\hline & $\begin{array}{l}\text { Facilidade na } \\
\text { amamentação }\end{array}$ & $\begin{array}{c}\text { "o bebê é amamentado mais cedo" Zakerihamidi et al. } 2014 \text { "ou porque } \\
\text { o leite é mais abundante". (Melchiori et al. 2009) "Facilita a } \\
\text { amamentação". (Nascimento et al. 2015) }\end{array}$ \\
\hline & Condição financeira & \begin{tabular}{|c} 
"É mais econômico". (Zakerihamidi et al. 2014) "sem recursos para pagar \\
pela cesariana". (Melchiori et al. 2009)
\end{tabular} \\
\hline & Dor momentânea & $\begin{array}{l}\text { "dor está limitada ao momento do parto." (Melchiori et al. 2009); "o } \\
\text { parto normal é melhor, a dor é só na hora, a recuperação é imediata." } \\
\text { (Feitosa et al. 2017) }\end{array}$ \\
\hline & Riscos reduzidos & $\begin{array}{c}\text { "por causa de comentários e sobre ter infecção." (Pimenta et al. 2013); } \\
\text { "oferece menor risco de hemorragia e de infecção." (Bittencourt et al. } \\
\text { 2013); "Todo mundo fala que é mais perigoso (a cesárea), pode pegar } \\
\text { infecção." (Pereira et al. 2011) }\end{array}$ \\
\hline \multirow{4}{*}{$\begin{array}{l}\text { Motivações para a } \\
\text { escolha da cesariana }\end{array}$} & $\begin{array}{l}\text { Rapideze } \\
\text { praticidade }\end{array}$ & \begin{tabular}{|c} 
"praticidade de escolher a data de nascimento de seu filho." (Bittencourt \\
et al. 2013); "por causa das férias do meu marido, pra ele poder estar \\
comigo." (Pires et al. 2010); "o trabalho do parto é mais rápido." \\
(Melchiori et al. 2009)
\end{tabular} \\
\hline & $\begin{array}{c}\text { Evitar } \\
\text { sofrimento/dor }\end{array}$ & $\begin{array}{l}\text { "Tive medo de encarar o parto normal." (Freire et al. 2011); "Eu não } \\
\text { queria sentir dor e eu preferia também, eu acho melhor, acho menos } \\
\text { sofrido." (Matão et al. 2016); "Medo das dores do parto, de não } \\
\text { conseguir ir até o final do parto, ter que fazer uma cesárea em cima da } \\
\text { hora." (Nakano et al. 2015) } \\
\end{array}$ \\
\hline & $\begin{array}{l}\text { Riscos/Sofrimento } \\
\text { do bebê }\end{array}$ & $\begin{array}{l}\text { "Eu acho cesárea melhor, porque não força tanto a criança, nem a mãe } \\
\text { fica sentindo dor." (Figueiredo et al. 2010); " Vagina é um canal rígido e } \\
\text { apertado que pode causar ferimentos à cabeça do bebê." (Faisal et al. } \\
\text { 2014) }\end{array}$ \\
\hline & $\begin{array}{c}\text { Indicações } \\
\text { obstétricas/Realizaçã } \\
\text { o de outros } \\
\text { procedimentos }\end{array}$ & $\begin{array}{c}\text { "Eu não tinha passagem, durante as consultas tive complicações e vim } \\
\text { para cá [...] foi indica ção médica [...] por conta da pressão que era alta, } \\
\text { aí foi ela (a médica) que escolheu o tipo." (Feitosa et al. 2017); "por } \\
\text { motivo de não ter passagem e como eu vou fazer a laqueadura." } \\
\text { (Figueiredo et al. 2010) "Por causa do cordão enrolado no pescoço a } \\
\text { médica achou mais seguro fazer cesárea." (Freire et al. 2011); "Todos } \\
\text { meus partos foram cesarianas, o médico disse que não tem condições de } \\
\text { ter normal." (Nascimento et al. 2015) }\end{array}$ \\
\hline $\begin{array}{l}\text { Fontes de informação } \\
\text { motivadoras }\end{array}$ & $\begin{array}{l}\text { Parto normal e } \\
\text { cesárea }\end{array}$ & $\begin{array}{c}\text { "e eu me informava, assim, pelas revistas, ou pela televisão, ou entrava na } \\
\text { internet para saber sobre o parto, a cesárea." (Velho et al. 2014); } \\
\text { "Família, familia sempre!", "Médicos, amigos, televisão, tudo!" } \\
\text { (Figueiredo et al. 2010); }\end{array}$ \\
\hline
\end{tabular}




\section{DISCUSSÃO}

Os estudos mostram que grande parte das mulheres ainda opta pela via vaginal de nascimento, no entanto a maioria não alcança esse objetivo. Quando a escolha da mulher é pelo parto cesariano, ela é atendida; o mesmo nem sempre ocorre com a escolha pelo parto normal (Freire et al. 2011). Um dos fatores recorrentes na opção pela cesárea ainda é a crença de que essa via de parto é livre de dor, além de possibilitar o planejamento para o momento do nascimento. Já em relação à opção pelo parto normal, a recuperação mais rápida está entre os motivos mais relatados.

A rápida recuperação após o parto vaginal se mostrou nos estudos analisados como um dos principais motivos para a escolha desta via de parto, o que pode ser indicar uma forma de resgatar da autonomia da mulher, tanto em relação aos cuidados com o bebê, como em relação cuidados consigo mesma (GUEDES et al. 2016). Diferentemente das necessidades de auxílio imposto pela cesariana, o parto vaginal implica em menor limitação física para a mulher (FIGUEIREDO et al. 2010).

O argumento de que essa via de parto é melhor para o bebê, em situações sem intercorrências, também foi relatado por grande parte das mulheres que escolheram o parto normal. A melhor adaptação respiratória do recém-nascido é um exemplo dos benefícios que este tipo de parto promove ao bebê. "Os mecanismos envolvidos no parto normal promovem estímulos táteis que estimulam o início da respiração no neonato sem comprometimento." (GUEDES et al. 2016).

Algumas mulheres citaram também a facilidade para iniciar a amamentação após o parto normal como uma das motivações para a escolha do parto vaginal. Guedes et al. (2016) coloca o parto normal como um evento facilitador do processo de amamentação, devido, geralmente, a um bom estado clínico e pouca limitação física, favorecendo o início precoce da amamentação.

Quanto à questão financeira, em estudo realizado no Irã, verificou-se que os profissionais de saúde, na tentativa de incentivar as mulheres a realizarem um parto normal, aumentaram os valores de seus honorários quando a gestante solicitou cesárea como um estímulo para que ela mude de ideia (ZAKERIHAMIDI et al. 2014). Isso mostra a importância de os profissionais se dedicarem ao incentivo do parto normal, de forma que não necessitem partir para este tipo de atitude, mas sim forneçam todas as informações necessárias para que a escolha da via de parto seja feita de forma lúcida. 
Um dos fatores mais citados pelas mulheres para optarem pela cesariana é o medo da dor, contudo, este fator não deveria ser decisório na tomada de decisão, principalmente quando são conhecidos métodos para alívio da dor durante o trabalho de parto, inclusive métodos não farmacológicos. Estas possibilidades deveriam ser explicadas à gestante durante todo o processo de gestação, principalmente nas consultas de pré-natal, subsidiando sua decisão e deixando o processo de parir o mais confortável possível. O medo do parto em si também foi citado nos artigos analisados. Domingues et al. (2014) refere resultados semelhantes em seu estudo que contou com a participação de 23.940 puérperas, apontando o medo do parto normal como fator determinante na tomada de decisão das mulheres.

É possível identificar também nos estudos analisados o descaso com a gestante nos períodos de pré-parto, parto e pós-parto associado à falta de acompanhante, condição motivadora para a escolha do parto cirúrgico. Weidle et al. (2014) evidencia em seu estudo que a experiência negativa no parto normal anterior é muitas vezes decisiva para que a mulher opte pela cesariana na última/atual gestação, considerando-se o trauma vivenciado por esta mulher na assistência ao seu parto.

A Portaria n. 2.418 MS/GM, de 02 de dezembro de 2005, regulamenta, em conformidade com o art. $1^{\circ}$ da Lei $n^{\circ} 11.108$, de 7 de abril de 2005, a presença de acompanhante para mulheres durante os períodos de pré-parto, parto e pós-parto imediato no Sistema Único de Saúde - SUS. No entanto, estudo realizado em duas maternidades filantrópicas do estado de Sergipe, que contou com a participação de 160 mulheres (gestantes, parturientes e puérperas), mostrou que $60 \%$ das participantes da pesquisa informaram não terem sido avisadas pela maternidade sobre o direito de ter um acompanhante durante o processo de parir, refere ainda que apenas $35 \%$ disseram ter recebido essa informação ainda no pré-natal e que $66,2 \%$ das participantes referiram não terem obtido permissão para ter um acompanhante nesse processo (SANTOS et al. 2016). A falta de informação das mulheres aliada ao desrespeito aos seus direitos por parte dos profissionais e das instituições de saúde tem prejudicado o processo de humanização do parto e do nascimento.

Sabe-se que a cirurgia cesariana não ocorre apenas devido ao pedido da mulher. Domingues et al. (2014) relatam que em seu estudo menos de $2 \%$ das participantes alegaram desejo pela cesárea. Um dos argumentos utilizados é a realização de outros procedimentos cirúrgicos concomitantemente à cesariana, como, por exemplo, a laqueadura tubária no momento do parto. No entanto, segundo a lei $n^{\circ}$ 9.263, de 12 de janeiro de 1996, é vedada a realização da laqueadura durante o parto ou aborto, salvo situações em que seja comprovada tal necessidade ou devido a sucessivas cesáreas anteriores. 
Os resultados de um estudo realizado em um município localizado no Vale do Taquari (WEIDLE et al. 2014) sugerem que as influências familiares e a via de parto já experimentada são fatores determinantes na opção da mulher pelo parto vaginal. Já em relação à cesariana, a indicação do profissional médico, junto com o medo do parto normal, foram os principais influenciadores. Weidle et al. (2014) cita ainda que nenhuma das mulheres que optaram pelo parto vaginal tiveram influência do médico. Estes resultados se assemelham aos encontrados nos estudos analisados nessa revisão, ressaltando também a influência de partos cirúrgicos anteriores na escolha pela cesárea (FREIRE et al. 2011; NASCIMENTO et al. 2015; NAKANO et al. 2015).

A ideia de que após realizar uma cesárea deve-se realizar obrigatoriamente outra cesárea no próximo parto ainda faz parte das crenças de muitas mulheres, bem como de profissionais. Viana et al. (2018) evidenciou que uma das principais indicações de cesárea, segundo dados dos prontuários analisados, é a realização prévia de cesárea. No entanto, a realização de cesárea anterior não é necessariamente uma contraindicação para o parto por via vaginal. Segundo o documento do Ministério da Saúde intitulado "Diretrizes de Atenção à Gestante: a operação Cesariana" (2015), em gestantes com cesariana prévia deve-se considerar as preferências e prioridades da mulher, os riscos e benefícios de uma nova cesariana e os riscos e benefícios de um parto vaginal após uma cesariana, incluindo o risco de uma cesariana de não planejada. (BRASIL, 2015)

É necessária atenção redobrada às mulheres primigestas, pois o parto realizado na primeira gestação tem grande chance de se repetir posteriormente. Nomura et al. (2004) relataram algumas complicações que podem estar relacionadas à via de parto utilizada. $\mathrm{O}$ estudo mostrou que entre 07 (sete) mulheres que tiveram hemorragia pós-parto e precisaram realizar uma histerectomia, 06 (seis) haviam realizado uma cesárea. Além disso, as complicações infecciosas, como endometrite e histerectomia por infecção, também tiveram uma maior incidência em mulheres que realizaram o parto cirúrgico. Apesar de as associações não serem significativas no estudo citado, é importante investigá-las mais a fundo a fim de obter um diagnóstico mais preciso.

A facilidade e praticidade da cesárea, evidenciadas pela possibilidade de agendar o nascimento dos filhos, foram citadas como motivadoras para a escolha da cesárea. Essa ideia aumenta o número de gestantes que são submetidas ao parto cirúrgico antes mesmo de entrarem em trabalho de parto, de forma a evitar o parto em um momento inconveniente para as mães, pais ou mesmo para os próprios profissionais.

O estudo de Viana et al. (2018) mostra que das 465 participantes que realizaram 
cesárea, 346 não entraram em trabalho de parto antes da realização do procedimento. Carneiro et al. (2015) cita a possibilidade de nascimento prematuro associada ao erro no cálculo da idade gestacional como um dos riscos envolvidos em parto agendado, aquele em que a gestante não entrou em trabalho de parto.

Existem também as mulheres que chegam à gestação sem uma escolha em mente, preferem aguardar o decorrer desta para tomar uma decisão mais embasada. Nesse sentido, percebe-se a importância de um atendimento de pré-natal de qualidade, com escuta qualificada e compartilhamento de informações que possam fornecer subsídios a esta gestante para que sua escolha pela via de parto ocorra de forma consciente e orientada (FEITOSA et al. 2017; FREIRE et al. 2011).

O enfermeiro tem papel fundamental no atendimento ao pré-natal de baixo risco na Atenção Básica. Nascimento et al. (2015) refere a importância da participação deste profissional em ações educativas no pré-natal como forma de tornar a assistência no período gravídico mais humanizada de forma a favorecer o resgate do protagonismo da mulher no processo de gestar e parir.

Outro fator considerado muito importante na tomada de decisão da mulher é a influência do ambiente no qual está inserida. A opinião dos familiares e dos amigos possui grande peso no processo de escolha, principalmente se a informação vem de alguém que já teve alguma experiência. As convicções e experiências dos familiares, quanto aos dois tipos de parto, exercem forte influência na via de parto escolhida (SILVA et al. 2011).

Os estudos apontam a falta de informações como uma das principais causas para a escolha pelo parto cirúrgico. Não informar a mulher sobre métodos para alívio da dor, fases do trabalho de parto, vantagens e desvantagens das vias de parto, tudo isso colabora para essa escolha.

A internet, os livros e as revistas têm se mostrado aliados das mulheres como fontes de informação, ajudando a suprir as falhas nas consultas de pré-natal quanto ao preparo da mulher para a escolha consciente da via de parto (VELHO et al. 2014). Silva et al. (2011), entretanto, destaca a possibilidade de as informações vinculadas a esses meios influenciarem negativamente na escolha do parto, com relatos assustadores de partos normais, por exemplo. Portanto, mesmo com essas fontes de informação, o profissional de saúde ainda deve se esforçar para que o máximo de dúvidas das gestantes sejam supridas, favorecendo uma escolha mais tranquila e consciente.

Tendo em vista a importância da influência dos profissionais de saúde na decisão da mulher pela via de parto, em 2017 o Ministério da Saúde, em parceria com a Empresa 
Brasileira de Serviços Hospitalares (EBSERH), a Associação Brasileira de Hospitais Universitários e de Ensino (ABRAHUE), o Ministério da Educação (MEC) e o Instituto Nacional de Saúde da Mulher, Criança e Adolescente Fernandes Figueira/ Fundação Oswaldo Cruz (IFF/FIOCRUZ), criou o projeto intitulado "Aprimoramento e Inovação no Cuidado e Ensino em Obstetrícia e Neonatologia (Apice on)”, tendo a Universidade Federal de Minas Gerais (UFMG) como instituição executora. O objetivo do projeto é qualificar a assistência obstétrica nos hospitais universitários, de ensino e/ou que atuam como unidade auxiliar de ensino, no âmbito da Rede Cegonha. A iniciativa dispõe-se a contribuir na formação de novos profissionais com a implementação das práticas baseadas em evidências, de acordo com os princípios da humanização, visando produzir impacto em toda a rede de serviços. (BRASIL, 2017)

Considera-se como limitação desta revisão a quantidade limitada de estudos realizados em outros países, além do Brasil, o que dificulta a identificação do cenário global no processo de tomada de decisão da mulher quanto à via de parto, bem como das diferenças culturais envolvidas nesse processo.

Esta revisão contribuiu para obter uma visão geral das principais motivações para a escolha do tipo de parto, favorecendo a identificação de pontos que precisam ser trabalhados na assistência, em especial na Atenção Básica, de forma a fornecer às gestantes melhores condições para tomada de decisão consciente.

\section{CONCLUSÃO}

Dentre as alegações mais relatadas para a escolha por um parto normal estão a recuperação puerperal mais rápida e os benefícios para a saúde do bebê. Já em relação à cesariana, os estudos são unânimes ao relatarem o medo da dor e do parto em si como os principais motivos para essa escolha.

Verifica-se uma falha no fornecimento de informações às gestantes durante o prénatal, fazendo com que elas tomem decisões baseadas nas opiniões de familiares, amigos ou da mídia, o que nem sempre é algo positivo.

Em nenhum dos estudos analisados a enfermagem foi referida como fonte de informação das mulheres, dado bastante preocupante se considerarmos que o pré-natal de baixo risco realizado nas Unidades Básicas de Saúde é de responsabilidade do enfermeiro. Esse profissional deve aproveitar a oportunidade para fornecer às gestantes as informações 
pertinentes que envolvem todo o processo de gestar e parir.

\section{REFERÊNCIAS}

BITTENCOURT, F.; VIEIRA, J. B.; ALMEIDA, A. C. C. H. Concepção de gestantes sobre o parto cesariano. Cogitare Enfermagem. v.18, n.3, p.515-20, 2013.

BRASIL. Ministério da Saúde, Gabinete do Ministro. Portaria no 2.418 , de 02 de dezembro de 2005. Regulamenta, em conformidade com o art. $1^{\circ}$ da Lei $n^{\circ} 11.108$, de 7 de abril de 2005, a presença de acompanhante para mulheres em trabalho de parto, parto e pós-parto imediato nos hospitais públicos e conveniados com o Sistema Único de Saúde - SUS.

BRASIL. Ministério da Saúde. Comissão Nacional de Incorporação de Tecnologias no SUS. Relatório de Recomendação. Diretrizes de Atenção à Gestante: a operação Cesariana. Ministério da Saúde. Secretaria de Ciência, Tecnologia e Insumos Estratégicos, Brasília, 2015.

BRASIL. Ministério da Saúde. Nascimentos por residência da mãe por ano tipo de parto / Nascidos vivos por residência da mãe por ano e tipo de parto. Brasília: Ministério da Saúde. Disponível em: <http://www2.datasus.gov.br/DATASUS/index.php?area=0205>.

BRASIL. Ministério da Saúde. Secretaria de Atenção à Saúde. Departamento de Ações Programáticas e Estratégicas. Coordenação Geral de Saúde das Mulheres. Coordenação Geral de Saúde da Criança e Aleitamento Materno. Aprimoramento e Inovação no Cuidado e Ensino em Obstetrícia e Neonatologia - Apice on. Ministério da Saúde, Brasília, 2017.

BRASIL. Presidência da República. Casa Civil. Subchefia para Assuntos Jurídicos. Lei no 9.263, de 12 de janeiro de 1996. Regula o $\S 7^{\circ}$ do art. 226 da Constituição Federal, que trata do planejamento familiar, estabelece penalidades e dá outras providências.

BRITO, A. O. Modelos de parto no Distrito Federal: perspectivas das mulheres e dos profissionais de saúde. 2013. 94 f., il. Monografia (Bacharelado em Saúde Coletiva)Universidade de Brasília, Brasília, 2013.

CARNEIRO, L. M. A. et al. Parto natural X parto cirúrgico: percepções de mulheres que vivenciaram os dois momentos. Revista de Enfermagem do Centro-Oeste Mineiro. v.5, n.2, p.1574-1585, 2015.

CHADWICK, R. J.; \& FOSTER, D. Technologies of gender and childbirth choices: Homebirth, elective caesarean and white femininities in South Africa. Feminism \& Psychology. v.23, n.3, p.317-338, 2012.

DINIZ, S. G.; CHACHAM, A. S. Dossiê humanização do parto. São Paulo: Rede Nacional Feminista de Saúde, Direitos Sexuais e Direitos Reprodutivos, 2002. Disponível em: < http://www.redesaude.org.br/home/conteudo/biblioteca/biblioteca/dossies-da-redefeminista/015.pdf>.

DOMINGUES, R. M. S. M. et al. Processo de decisão pelo tipo de parto no Brasil: da preferência inicial das mulheres à via de parto final. Caderno de Saúde Pública, Rio de Janeiro, v.30, supl. 1, p. S101-S116, 2014.

ENSP. Prematuridade provocada por intervenção médica chega a $40 \%$ no Brasil. 
Disponível em: <http://www.ensp.fiocruz.br/portal-ensp/informe/site/materia/detalhe/41005>. FAISAL, I.; MATINNIA, N.; HEJAR, A. R.; \& KHODAKARAMI, Z. Why do primigravidae request caesarean section in a normal pregnancy? A qualitative study in Iran. Revista Midwifery, v. 30, n.2, p. 227-33, 2014.

FEITOSA, R. M. M. et al. Fatores que influenciam a escolha do tipo de parto na percepção das puérperas. Revista de Pesquisa: Cuidado é Fundamental. v.9, n.3, p. 717-726, 2017.

FIGUEIREDO, N. S. V. et al. Fatores culturais determinantes da escolha da via de parto por gestantes. HU Revista, Juiz de Fora, v. 36, n. 4, p. 296-306, 2010.

FREIRE, N. C. et al. Parto normal ou cesárea? a decisão na voz das mulheres. Revista Baiana de Enfermagem, v. 25, n. 3, 2011.

GUEDES, G. W. et al. Conhecimentos de gestantes quanto aos benefícios do parto normal na consulta pré-natal. Revista de enfermagem UFPE online, Recife, v.10, n.10, p. 3860-7, 2016.

LEAL, M. do C. et al. Prevalence And Risk Factors Related To Preterm Birth In Brazil. Reproductive Health. v.13, Suppl 3, p. 127, 2016.

MATÃO, M. E. L.; PINHEIRO, T. M.; MARQUES, S. I. R.; \& de MIRANDA, D. B. Fatores que influenciam na indicação da via de parto. Revista de Enfermagem do CentroOeste Mineiro. v.1, n.6, p.2066-2080, 2016.

MELCHIORI, L. E.; MAIA, A. C. B.; BREDARIOLLI, R. N.; \& HORY, R. I. Preferência de Gestantes pelo Parto Normal ou Cesariano. Interação em Psicologia, Curitiba, v.13, n.1, p. 13-23, 2009.

MENDES, K. D. S.; SILVEIRA, R. C. de C. P.; GALVÃO, C. M. Revisão integrativa: método de pesquisa para a incorporação de evidências na saúde e na enfermagem. Texto $\&$ contexto enfermagem, v. 17, n. 4, 2008.

NAKANO, A. R.; BONAN, C.; \& TEIXEIRA, L. A. A normalização da cesárea como modo de nascer: cultura material do parto em maternidades privadas no Sudeste do Brasil. Physis Revista de Saúde Coletiva, Rio de Janeiro, v.25, n.3, p.885-904, 2015.

NASCIMENTO, R. R. P. et al. Escolha do tipo de parto: fatores relatados por puérperas. Revista Gaúcha de Enfermagem, v. 36, p. 119-126, 2015.

NOMURA, R. M. Y., ALVES, E. A., \& ZUGAIB, M. Complicações maternas associadas ao tipo de parto em hospital universitário. Revista de Saúde Pública, v.38, n.1, p. 9-15, 2004.

PEREIRA, R. R.; FRANCO, S. C.; BALDIN, N. Representações Sociais e Decisões das Gestantes sobre a Parturição: protagonismo das mulheres. Saúde e Sociedade São Paulo, v.20, n.3, p.579-589, 2011.

PIMENTA, L. F.; da SILVA, S. C.; BARRETO, C. N., \& RESSEL, L. B. A cultura interferindo no desejo sobre o tipo de parto. Revista de Pesquisa: Cuidado e Fundamental. v. 6, n.3, p. 987-997, 2014.

PIRES, D. et al. A influência da assistência profissional em saúde na escolha do tipo de parto: um olhar sócio antropológico na saúde suplementar brasileira. Revista Brasileira Saúde Materno Infantil, Recife. v.10, n.2, p.191-197, 2010. 
SANTOS, E. C. P. et al. Conhecimento e aplicação do direito de acompanhamento na gestação e parto. Enfermagem em Foco. v.7, n.3/4, p.61-65, 2016.

SILVA, H. M.; RIBEIRO, C. D. \& COSTA, A. R. Acompanhamento de gestantes: nível de informação e influências de familiares, amigos e da mídia para a decisão do tipo de parto. Conexão ciência (Online), v.6, n.1, p.32-40, 2011.

SOUSA, R. G., \& SANTANA, A. B. Risco de integridade da pele prejudicada: avaliação e conduta de enfermagem frente às úlceras por pressão (UPP) em pacientes em terapia intensiva. Universitas: Ciências da Saúde, Brasília, v. 14, n. 2, p. 167-173, 2016.

VELHO, M. B.; SANTOS, E. K. A.; \& COLlAÇO, V. S. Parto normal e cesárea: representações sociais de mulheres que os vivenciaram. Revista Brasileira de Enfermagem. v.67, n.2, p. 282-9, 2014.

VIANA, T. G. F. et al. Motivo da realização de cesárea segundo relato das mães e registros de prontuários em maternidades de belo horizonte. REME - Revista Mineira de Enfermagem. v. 22 e-1073, 2018.

WEIDLE, W. G., MEDEIROS, C. R. G., GRAVE, M. T. Q., \& DAL BOSCO, S. M. Escolha da via de parto pela mulher: autonomia ou indução?. Caderno de Saúde Coletiva. Rio de Janeiro, v.22, n.1, p. 46-53, 2014.

ZAKERIHAMIDI, M.; ROUDSARI, R. L.; KHOEI, E. M.; \& KAZEMNEJAD, A. Decisionmaking for vaginal delivery in the North of Iran: A focused ethnography. Iranian journal of nursing and midwifery research. v.19, n.7 Suppl1, S37. 2014. 


\section{ANEXO A}

\section{Critical}

A ppraisal

S kills

$\mathbf{P}$ rogramme

\section{0 questions to helpyou makesense of qualitativeresearch}

\section{How to use this appraisal tool}

Three broad issues need to be considered when appraising a qualitative study:

Are the results of the study valid?

(Section A)

What are the results?

(Section B)

Will the results help locally?

(SectionC)

The 10 questions on the following pages are designed to help you think about these issues systematically. The first two questions are screening questions and can be answered quickly. If the answer to both is "yes", it is worth proceeding with the remaining questions.

There is some degree of overlap between the questions, you are asked to record a "yes", "no" or "can't tell" to most of the questions. A number of italicised prompts are given after each question. These are designed to remind you why the question is important. Record your reasons for your answers in the spaces provided.

These checklists were designed to be used as educational pedagogic tools, as part of a workshop setting, therefore we do not suggest a scoring system. The core CASP checklists (randomised controlled trial \& systematic review) were based on JAMA 'Users' guides to the medical literature 1994 (adapted from Guyatt GH, Sackett DL, and Cook DJ), and piloted with health care practitioners.

For each new checklist a group of experts were assembled to develop and pilot the checklist and the workshop format with which it would be used. Overthe years overall adjustments have been made to the format, but a recent survey of checklist users reiterated that the basic format continues to be useful and appropriate.

Referencing: we recommend using the Harvard style citation, i.e.:

Critical Appraisal Skills Programme (2017). CASP (insert name of checklist i.e. Qualitative Research) Checklist. [online] Available at: URL. Accessed: Date Accessed.

(C)ASP this work is licensed under the Creative Commons Attribution - Non Commercial-Share A like. To view a copy of this license, visit http://creativecommons.org/licenses/by-nc-sa/3.0/www.casp-uk.net 


\section{Screening Questions}

\section{Was thereaclear statement of the aims}

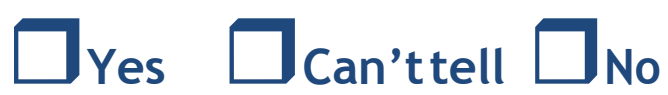

\section{of the research?}

HINT: Consider

- What was the goal of the research?

- Why it was thought important?

- Its relevance

2. Is a qualitative methodology appropriate?

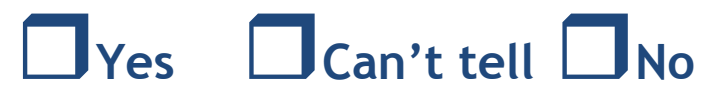

HINT: Consider

- If the research seeks to interpretorilluminate the actions and/or subjective experiences of research participants

- Is qualitative research the right methodology for addressing the research goal?

\section{Is it worth continuing?}

\section{Detailed questions}

3. Was the research design appropriate to $\square$ Yes $\quad \square$ can'ttell $\square_{\text {No }}$ address the aims of the research?

HINT: Consider

- If the researcher has justified the research design (E.g. have they discussed how they decided which method to use)? 
4. Was the recruitment strategy appropriate to the aims of the research?

HINT: Consider

- If the researcher has explained how the participants were selected

- If they explained why the participants they selected were the most appropriate to provide access to the type of knowledge sought by the study

- If there are any discussions around recruitment (e.g. why some people chose not to take part)

\section{Was the data collected in a way that addressed}

\section{the research issue?}

\section{HINT: Consider}

- If the setting for data collection was justified

- If itisclearhowdatawerecollected(e.g. focus group, semi-structured interview etc.)

- If the researcher has justified the methods chosen

- If the researcher has made the methods explicit (e.g. for interview method, is there an indication of how interviews were conducted, or did they use a topic guide)?

- If methodsweremodifiedduring thestudy. Ifso, has the researcher explained how and why?

- If the form of dataisclear (e.g. tape recordings, video material, notes etc)

- If the researcher has discussed saturation of data

\section{Has the relationship between researcher and participants been adequately considered?}

HINT: Consider

- If the researcher critically examined their own role, potential bias and influence during

(a) Formulation of the research questions

(b) Data collection, including sample recruitment and choice of location

How the researcher responded to events during the study and whether they considered the implications of any changes in the research design 


\section{Have ethical issues been taken into consideration?}

HINT: Consider

- If thereare sufficient details of how the research was explained to participants for the reader to assess whether ethical standards were maintained

- If the researcher has discussed issues raised by the study (e.g. issues around informed consentor confidentiality or how they have handled the effects of thestudy onthe participants during and after thestudy)

- If approval has been sought from the ethics committee

\section{Was the data analysis sufficiently rigorous?}

\section{HINT: Consider}

- If there is an in-depth description of the analysis process

- If thematic analysis is used. If so, is itclearhowthe categories/themes were derived from the data?

- Whether the researcher explains how the data presented were selected from the original sample to demonstrate the analysis process

- If sufficient data are presented to support the findings

- To what extent contradictory data are taken into account Whether the researcher critically examined their own role, potential bias and influence during analysis and selection of data for presentation 


\section{Is there a clear statement of findings?}

HINT: Consider

- If the findings are explicit

- If there is adequate discussion of the evidence both for and against the researchers arguments

- If the researcher has discussed the credibility of their findings (e.g.triangulation, respondentvalidation, more than oneanalyst)

- Ifthe findings are discussedin relation to the original research question

\section{How valuable is the research?}

HINT: Consider

- If the researcher discusses the contribution the study makes to existing knowledge or understanding e.g. do they consider the findings in relation to current practice or policy?, or relevant research-based literature?

- If they identify new areas where research is necessary

- If the researchers have discussed whether or how the findings can be transferred to other populations or considered other ways the research may be used 